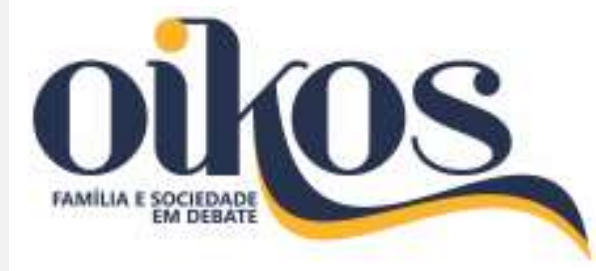

COSTA, Elimara Oliveira; BIFANO, Amelia Carla Sobrinho. Representações, subjetividade e uso de tecnologias domésticas por idosos. Oikos: Família e Sociedade em Debate, v. 30, n. 1, p. 68-86, 2019.

\title{
Representações, subjetividade e uso de tecnologias domésticas por idosos ${ }^{1}$
}

\author{
Representations, subjectivity and use of domestic technologies by elderly
}

\author{
Elimara Oliveira Costa² \\ Amelia Carla Sobrinho Bifano ${ }^{3}$
}

\begin{abstract}
Resumo
Projeções recentes do IBGE e da PNAD contínua apontam que a expectativa de vida dos brasileiros está aumentando significativamente. Concomitantemente ao expressivo envelhecimento da sociedade brasileira, vivenciamos também um crescente avanço tecnológico, provocando alterações em diferentes aspectos da vida cotidiana dos sujeitos. Neste artigo são apresentados os resultados de uma pesquisa guiada sobre a relação entre representações sociais e uso de tecnologias domésticas por pessoas idosas. A pesquisa de cunho qualitativo, dentro do contexto de um estudo de caso, foi realizada com um grupo de 38 idosos, residentes no município de Viçosa, interior da Zona da Mata Mineira, durante os meses de maio a outubro de 2017. Para coleta dos dados foi aplicado um questionário semiestruturado. As informações obtidas foram analisadas seguindo os pressupostos teóricos e metodológicos da Análise de Conteúdo de Bardin (2009). O estudo evidenciou que a representação dos idosos acerca do "ser idoso" é distante da realidade vivenciada por eles, visto que as representações que possuem acerca do envelhecimento são carregadas de estereótipos negativos. Foi observado que essas representações aparecem de maneira direta e indireta, definidas por sistemas e práticas compartilhadas socialmente. Concluiu-se que a relação entre idosos e tecnologias domésticas aparece como inserida em uma produção subjetiva social e individual, possuindo um valor central na forma como os sujeitos se relacionam com os artefatos tecnológicos e como percebem a si mesmos.
\end{abstract}

Palavras-chave: Envelhecimento; Subjetividade; Tecnologia; Representação de idosos; Representação de artefatos tecnológicos.

\begin{abstract}
Recent projections by the IBGE and the continuous PNAD show that the life expectancy of Brazilians is increasing significantly. Concomitantly with the expressive aging of Brazilian society, we also experience a growing technological advance, provoking changes in different aspects of the daily life of the subjects. This article presents the results of a guided research on the relationship between social representations and the use of domestic technologies by older people. The qualitative research, within the context of a case study, was carried out with a group of 38 elderly people, living in the municipality of Viçosa, in the interior of Zona da Mata Mineira, from May to October 2017. A semistructured questionnaire was applied. The information obtained was analyzed, following the theoretical and methodological assumptions of the Bardin Content Analysis (2009). The study showed that the representation of the elderly about the "old being" is far from the reality experienced by them, since the representations they have about aging are loaded with negative stereotypes. It was observed that these representations appear directly and indirectly, defined by socially shared systems and practices. It was concluded that the relationship between the elderly and domestic technologies appears as inserted in a subjective social and individual production, having a central value in the way the subjects relate to the technological artifacts and how they perceive themselves.
\end{abstract}

Key-words: Aging; Subjectivity; Technology Representation of the elderly; Representation of technological artifacts.

\footnotetext{
${ }^{1}$ Este artigo faz parte da dissertação intitulada: "Uso de Tecnologias Domésticas por Idosos", defendida em julho de 2018 no Programa de Pós-Graduação em Economia Doméstica da Universidade Federal de Viçosa, Viçosa-MG, Brasil.

2 Mestre em Economia Doméstica pelo Programa de Pós-Graduação em Economia Doméstica da Universidade Federal de Viçosa. E-mail: elimara.costa@ufv.br

3 Doutora em Engenharia de Produção pela Universidade de São Paulo, Professora Adjunta da Universidade Federal de Viçosa, Viçosa, MG, Brasil. E-mail: abifano@ufv.br
} 


\section{INTRODUÇÃO}

O presente estudo apresenta os resultados de uma pesquisa guiada sobre a articulação entre subjetividade e representações sociais no processo de subjetivação de pessoas idosas, no que se refere ao uso de tecnologias domésticas. Além disso, buscou-se evidenciar como o aspecto subjetivo da representação de "ser idoso" repercute na forma que o próprio idoso entende o papel da tecnologia doméstica em seu cotidiano.

Com projeções de taxas de crescimento de mais de 4\% ao ano, no período entre 2012 e 2022, a população idosa no Brasil passa de 14,2 milhões em 2000, para 19,6 milhões em 2010, sendo capaz de atingir 41,5 milhões em 2030, e 73,5 milhões em 2060 (BORGES; CAMPOS; SILVA, 2015). Estima-se um aumento médio de mais de 1,0 milhão de idosos anualmente nos próximos 10 anos. Já o número de idosos acima de 80 anos poderá quadruplicar, sendo capaz de alçar a média de 2,0 milhões em 2050 (ONU, 2016).

Peixoto; Clavairolle (2005) afirmam que o crescimento da população idosa coincide com o acelerado desenvolvimento tecnológico das sociedades ocidentais. Para as autoras, ao contrário do que é difundido pelo senso comum, os idosos apresentam interesse no uso de diferentes tipos de tecnologias. Entretanto, esse interesse depende principalmente do tipo de produto a eles ofertado. Todavia, percebe-se a existência de barreiras na utilização de diferentes tipos de tecnologias pelos idosos, como a percepção negativa que possuem de si, vendo-se incapazes de usar tais produtos.

Autores como (AMARAL JUNIOR, 2013; CAMARANO; KANSO; MELLO, 2004) ressaltam que a percepção negativa de si mesmo é resultado de uma visão originária de estereótipos da sociedade ocidental, onde a velhice é compreendida como o estágio da decadência, da improdutividade, da dependência, sem papéis sociais, que vivencia apenas perdas. Para Amaral Junior, essa visão negativa, incorporada a outras questões como, por exemplo, dificuldade de interpretação e compreensão do produto, interfere significativamente na forma como os idosos lidam com as tecnologias.

As representações sociais, segundo Moscovici (2007), devem ser vistas como uma forma específica de compreender e comunicar o que já se sabe. Ao se dizer que as representações são sociais, diz-se que elas são simbólicas, possuindo tanto elementos perceptuais como cognitivos. As representações são sociais por serem um fato psicológico, ou seja, por possuírem um aspecto impessoal, no sentido de pertencerem a todos; elas são as representações de outros, pertencentes a outras pessoas ou a outro grupo, e percebidas afetivamente como pertencentes ao ego (MOSCOVICI, 2007). 
De acordo com Gonzalez Rey (2006), a teoria das representações sociais deu início ao estudo dos processos de subjetivação da vida social. As representações sociais constituem a "realidade social" em que o sujeito se situa, atribuindo um valor de realidade. Sendo assim, o valor de realidade conferido é uma forma de preservar a subjetividade.

A subjetividade sempre esteve associada como pertencente ao indivíduo, visto que, pela sua orientação individual, é entendida como natureza interna do sujeito. Em seus trabalhos, González Rey destaca um conceito relevante no estudo da subjetividade, o sentido subjetivo. De acordo com o autor, o sentido subjetivo é entendido como uma unidade inseparável entre o simbólico e o emocional, no qual um evoca o outro, apesar de não ser determinado por ele (GONZÁLEZ REY, 2006). Ainda segundo González Rey, o sentido subjetivo está sempre associado ao simbólico, produzido pela cultura, bem como conceitos e práticas sociais, que, para o autor, são a "matéria-prima" da subjetividade.

\section{REFERENCIAL TEÓRICO}

\section{O conceito de envelhecimento: uma construção social}

Envelhecer, na contemporaneidade, é entendido como um complexo e heterogêneo processo, ao ser considerado, por um lado, como único e singular em sua essência, e, por outro, como universal, uma vez que envolve mudanças intrínsecas ao curso natural da vida dos seres humanos (NERI, 2001). Sendo assim, de acordo com Teixeira et al. (2015), o envelhecimento humano deve ser entendido em sua totalidade, levando em consideração os aspectos biológicos, psicológicos e sociais, ao se tratar de "[...] um processo multifatorial, não havendo uma padronização do seu estabelecimento" (TEIXEIRA et al., 2015, p. 507).

Segundo Mendes et al. (2005, p. 424), "todos os seres vivos são regidos por um determinismo biológico, sendo que o envelhecimento envolve processos que implicam na diminuição gradativa da possibilidade de sobrevivência [...]". Para estes autores, os processos que incidem sobre os indivíduos são acompanhados por alterações tanto na aparência como no comportamento, na experiência, bem como em seus papéis sociais. O envelhecimento é parte integrante e constitucional do curso de vida de cada indivíduo, sendo a fase da vida onde emergem as experiências e peculiaridades vivenciadas, que integram a formação do idoso.

Do ponto de vista psicológico, o envelhecimento é definido, de acordo com Teixeira et al. (2015), a partir do senso e do julgamento subjetivo da idade, considerando a forma como o indivíduo vivencia e percebe as mudanças naturais do envelhecer. Em outras palavras, a idade 
psicológica é entendida como a "[...] maneira como cada indivíduo avalia em si mesmo a presença ou a ausência de marcadores biológicos, sociais e psicológicos da idade, com base em mecanismos de comparação social mediados por normas etárias” (NERI, 2001, p. 43). Apesar de existir discrepância entre as alterações corporais inerentes ao envelhecimento e a percepção que o sujeito tem de si, segundo Teixeira et al. (2015), a mente é capaz de criar estratégias para lidar com as mudanças físicas e sociais, contribuindo para que o idoso encare de forma mais naturalizada o envelhecer.

O envelhecimento, do ponto de vista social, acontece no âmbito da relação entre os comportamentos vistos socialmente como "adequados" e as mudanças biológicas, psicológicas e sociais que acometem o sujeito que envelhece (BAPTISTA, 2013). De acordo com Teixeira et al. (2015), o padrão de comportamento imposto pela sociedade atua como uma espécie de relógio social, julgando o que é apropriado e inapropriado para cada faixa etária. Baptista (2013) afirma que esse relógio social é internalizado pelo próprio sujeito, sendo reforçado por ele ao longo de sua vida.

Magalhães (1989) discorre ainda sobre outra forma de determinação do envelhecimento, o aspecto cronológico. Segundo o autor, a idade cronológica está intimamente relacionada com o calendário, que ao passar do tempo representa a idade do ser humano em números. Para Camarano et al. (1999), apesar de ser o mais utilizado na caracterização do sujeito como idoso, uma das consequências do uso da idade para essa definição é o poder prescritivo contido no mesmo, devido à sociedade criar expectativas em relação aos papéis sociais daqueles com o status de idoso, exercendo diversas formas de coerção para que esses papéis se cumpram, independentemente das características particulares de cada indivíduo.

Moreira; Nogueira (2008) afirmam ser possível observar uma espécie de preconceito em relação à idade, o que reflete em uma tendência de marginalização do envelhecer, associando o velho a algo pejorativo, e não como uma fase composta por aspectos positivos e negativos. Ainda segundo Moreira; Nogueira (2008), o termo ageism é utilizado para se referir ao tratamento preconceituoso e marginalizante com relação à faixa etária dos seres humanos.

O modelo capitalista, fundamentado na ideia de produtividade, também contribuiu para que a velhice obtivesse um lugar marginalizado socialmente, à medida que o sujeito perde sua capacidade de oferecer sua força de trabalho, diminuindo seu valor social (MENDES et al., 2005; MOREIRA; NOGUEIRA, 2008). Diante dessa realidade, é possível perceber o estigma presente no envelhecer, sobretudo o de "ser velho". Compreende-se que, desde o seu nascimento, o ser humano é inserido em uma sociedade permeada de representações sociais e estigmas negativos referentes à sua própria condição. Esse processo caracteriza-se como uma ameaça à 
autoestima e aceitação de si, contribuindo para torná-lo vulnerável a sofrimentos psíquicos e enfermidades de diversas naturezas (MOREIRA; NOGUEIRA, 2008; TEIXEIRA et al., 2015).

A sociedade contemporânea nos moldes do capitalismo é marcada pelos avanços da ciência e pelas conquistas alcançadas na construção de conhecimentos e progressos tecnológicos, que objetivam o prolongamento da vida humana. Todavia, essa evolução trouxe consigo a ilusão de uma juventude eterna, caracterizada pela resistência ao envelhecer (MOREIRA; NOGUEIRA, 2008). Para as autoras, os idosos que não aderem a esse "padrão" de comportamento esperado socialmente passam a ser vistos como descuidados, com defeitos que precisam ser escondidos ou disfarçados. Dessa forma, compreende-se um despreparo para acolher e definir o papel de quem envelhece, sendo possível perceber um paradoxo, no qual a velhice é ampliada, porém, não se quer saber dela.

É importante ressaltar que "o papel social dos idosos é um fator importante no significado do envelhecimento, pois o mesmo depende da forma de vida que as pessoas tenham levado, bem como das condições atuais em que se encontram" (MENDES et al., 2005, p. 424). Schneider; Irigaray (2008), por sua vez, salientam que as associações negativas relacionadas à velhice atravessam os séculos e, ainda hoje, mesmo com diversos recursos para prevenir doenças e retardá-las, a velhice é temida por muitas pessoas, sendo percebida como uma etapa detestável.

Em síntese, a velhice é entendida como construção social, uma vez que é resultado da:

[...] "invenção" de processos sociais e psicossociais, a velhice e o idoso emergem da dinâmica demográfica, do modo de produção econômica, da estrutura e organização de grupos e classes sociais, dos valores e padrões culturais vigentes, das ideologias correntes e dominantes e das relações entre Estado e a Sociedade Civil (MAGALHÃES, 1989, p.16).

Diante do exposto, observa-se que estabelecer critérios para demarcar o início da velhice é uma tarefa delicada, uma vez que é necessário levar em consideração aspectos individuais e o contexto em que o sujeito que envelhece está inserido. Dessa forma, torna-se necessário considerar como os determinantes macro e microssociais agem, sejam de forma combinada, contraditória, ambígua, conflitiva ou concorrente, delineando as diversificadas e contrastantes realidades dos idosos nos contextos nacionais e regionais de nossa sociedade (MAGALHÃES, 1989).

Observa-se na literatura uma diversidade de nomenclaturas e discussões relacionadas à categorização dos indivíduos idosos, demonstrando a subjetividade envolvida na temática. Cabe ressaltar o cuidado necessário por parte dos pesquisadores, que, ao estudarem questões relacionadas ao envelhecer, levem em questão também seus aspectos subjetivos. 


\section{A produção subjetiva das representações}

De acordo com Molon (2008), as temáticas sujeito e subjetividade surgiram por meio da ciência moderna. Suas emergências na psicologia foram fortemente influenciadas pelo pensamento naturalista e positivista, sendo subordinadas à disciplina, ao controle, à adaptação, à instrumentalidade e à utilidade.

Optou-se por discutir alguns conceitos básicos relacionados à subjetividade segundo a perspectiva de Lev Semióniovich Vygotsky. Entre os estudiosos que se baseiam nos princípios propostos por Vygotsky e analisam a constituição do sujeito priorizando a dimensão subjetiva, destaca-se a presença significativa de Fernando Luis González Rey.

A subjetividade pode ser definida como uma forma complexa de organização do psicológico, onde se integram, formando novas unidades, os processos simbólicos e emocionais, que tipificam as formas complexas do funcionamento do homem (GONZÁLEZ REY, 2005).

Para González Rey (2006) a subjetividade não é uma cópia, nem um reflexo do mundo real, mas uma produção humana de caráter simbólico e de sentido que, dentro da "realidade social" em que o homem vive, Ihe permite diferentes opções de vida cotidiana, além do seu desenvolvimento como indivíduo. O sentido subjetivo está em constante construção, sendo expresso por meio das ações. Um exemplo prático para se compreender como ocorre esse processo são as imagens. Uma imagem pode evocar emoções mesmo não estando associadas a um determinado contexto e, por sua vez, pode gerar novas imagens em um processo infinito, marcado pelos processos e comportamentos presentes nas ações dos indivíduos. Em outras palavras, o sentido subjetivo representa a maneira como a realidade se transforma em subjetiva, sendo alimentado pelas experiências vivenciadas. Dessa forma, toda atividade humana tem um momento subjetivo que não pode ser ignorado, o que até hoje foi profundamente desconhecido em muitos campos da atividade humana.

O sujeito é descrito por González Rey como uma síntese de integração e desintegração estabelecida entre a subjetividade social e a subjetividade individual, sempre em processo de constituição e reconstituição (ROSSATO; MARTÍNEZ, s/data). A subjetividade individual é marcada pela expressão de um sujeito concreto, envolvido em uma organização que integra o seu funcionamento psicológico. Já a subjetividade social é caracterizada pelas configurações subjetivas das pessoas e dos grupos que se articulam nos diversos espaços, momentos e níveis da vida social (TACCA; GONZÁLEZ REY, 2008).

A questão da subjetividade se faz presente à medida que se identifica a representação 
social como "[...] uma organização simbólica sobre a qual se desenvolvem as diferentes práticas e relações sociais dos membros de um grupo, instituição e comunidade, o que representa uma produção subjetiva" (GONZÁLEZ REY, 2006, p.70). Sendo assim, as representações sociais constituem a "realidade social" em que o sujeito se situa, ou seja, aquela que o indivíduo atribui um valor de realidade. O valor de realidade, para González Rey (2006), é atribuído como uma forma de preservar a subjetividade. Para o autor, "a subjetividade não é uma cópia, nem um reflexo do mundo real, é uma produção humana de caráter simbólico e de sentido que, dentro da "realidade social" em que o homem vive, lhe permite as diferentes opções de vida cotidiana e de seu desenvolvimento" (Id Ibid, p.70).

\section{PROCEDIMENTOS METODOLÓGICOS}

Fizeram parte do estudo 38 idosos, sendo 27 do sexo feminino e 11 do sexo masculino, com idades entre 63 e 81 anos. Cabe ressaltar que estes idosos fazem parte do cadastro do Laboratório Interfaces, lotado no Departamento de Economia Doméstica, na Universidade Federal de Viçosa.

Foi utilizado um questionário semiestruturado, entre os meses de maio e outubro de 2017 , para a coleta de dados. Para a aplicação do questionário foi realizado um primeiro contato com os idosos via telefone, no qual foram explicados os objetivos da pesquisa, e identificou-se o interesse dos mesmos em colaborar para realização do estudo. Posteriormente, foi realizada uma visita nos locais indicados pelos idosos, em data e horários preestabelecidos, conforme a escolha de cada um. Nessa visita foi entregue o Termo de Consentimento Livre e Esclarecido (TCLE), e novamente explicados os objetivos da pesquisa, a fim de deixar os participantes mais esclarecidos e confortáveis.

Os dados foram tratados e analisados por meio da Análise de Conteúdo de Bardin (2009). Esta técnica trata-se de um conjunto de instrumentos metodológicos aplicados em "discursos" diversificados. É considerado empírico, por depender do tipo de "fala" a que se dedica e do tipo da interpretação a que se objetiva.

\section{RESULTADOS E DISCUSSÕES}

Com base na análise do conteúdo dos dados obtidos por meio do questionário semiestruturado e nos pressupostos teóricos que nortearam este estudo, os resultados foram organizados em dois tópicos, a fim de facilitar sua apresentação e discussão. 


\section{Representação, percepção subjetiva de "ser idoso" e do uso de tecnologias}

Nas falas dos participantes pode ser observada sua percepção sobre o que é "ser idoso", e o papel da tecnologia na vida das pessoas idosas.

A "participante 2", ao explicar a importância e a facilidade proporcionada pelo uso do tanquinho e do forno de micro-ondas em seu cotidiano, se refere ao indivíduo idoso como "pessoa de idade". Segundo a participante, os idosos não "têm como ficar torcendo roupa", ou seja, a atividade sem a presença do eletrodoméstico não poderá se concretizar. O uso do microondas é vantajoso, pois dispensa o uso do gás de cozinha. A tecnologia é vista como uma forma de ajuda para as pessoas idosas, na opinião da "participante 7", visto que "o idoso não tem força mais", afirma ela.

[...] porque você vê, igual o tanquinho, a pessoa de idade não tem como ficar torcendo roupa. O micro-ondas também [...] para esquentar o leite. É mais fácil que você ligar o gás (Participante 2; 68 anos).

Facilita muito porque o idoso não tem força mais e, aí pede ajuda né! (Participante 29; 71 anos).

A "participante 23" diz acreditar que ninguém possui dificuldades em utilizar eletrodomésticos, inclusive os idosos, pois "hoje estão muito espertos". A idosa afirma que ela não tem dificuldade alguma. Ressalta que os eletrodomésticos facilitam a vida dos idosos. Entretanto, ao dizer a frase "os eletrodomésticos facilitam as atividades deles", a participante se refere ao sujeito idoso como algo fora de sua realidade, ou seja, ela não se identifica como uma pessoa idosa.

\footnotetext{
Menina, assim, eu não sei se tem algum idoso que tem... Eu acho que os idosos hoje estão muito espertos. Acho que ninguém tem dificuldade não, eu não tenho. Eu acho que os eletrodomésticos facilitam as atividades deles (Participante 23; 74 anos).

É mais, tem mais dificuldade depois quando vai ficando mais idosos (Participante 25; 67 anos).
}

A "participante 25" acredita que as dificuldades em utilizar eletrodomésticos surgem à medida que as pessoas vão ficando mais velhas.

Segundo Silva (2008), o significado depreciativo associado aos indivíduos considerados idosos surgiu concomitantemente ao desenvolvimento dos meios de produção capitalista, sendo consolidado nas pessoas consideradas inaptas para o trabalho devido à idade avançada. Para Rozendo; Justo (2011), na contemporaneidade os idosos raramente se enxergam como idosos, 
no sentido conotativo do temo já explicitado. Entretanto, ao se referirem à velhice, se posicionam como algo distante de sua realidade, o que permite compreender a existência de uma tentativa de se afastar das imagens pejorativas associadas ao envelhecimento.

Raymundo (2013) afirma que o uso de tecnologias garante aos indivíduos uma maior facilidade e independência nas atividades da vida diária. Contudo, é necessário ressaltar que os idosos têm manifestado dificuldades em acompanhar e compreender o crescente avanço tecnológico, o que contribui para o sentimento de exclusão. Dessa forma, os que não se adaptam ao "novo" são deixados à margem desta evolução (PEREIRA; NEVES, 2011).

Segundo a "participante 27", a tecnologia é vista como uma novidade, e sua importância se modifica de acordo com o indivíduo que dela faz uso. Em sua fala, a idosa afirma que "tem muito idoso que não aceita", ou seja, os idosos são, em sua maioria, refratários a "novas tecnologias".

Depende também da pessoa né! Tem muito idoso que não aceita essas novidades (Participante 27; 66 anos).

Depende do eletrodoméstico né! Eu acredito que o micro-ondas pode ser útil, bastante útil [...] porque eu acho também que as pessoas mais velhas não gostam, não aceitam esses eletrodomésticos não (Participante 09; 64 anos).

A "participante 09" alega que "as pessoas mais velhas" não aceitam as tecnologias domésticas, pois não gostam dos novos eletrodomésticos presentes no mercado. Entretanto, acredita que a aceitação de um artefato tecnológico pelo idoso depende de sua utilidade.

A rejeição de novas tecnologias por idosos pode ser interpretada como um sentimento de ansiedade de se ver diante de um produto que não fez parte de sua cultura técnica, necessitando de um aprendizado especializado (PEIXOTO; CLAVAIROLLE, 2005). Para as autoras, a socialização de um artefato tecnológico depende de dois fatores principais: possibilidade de integração do objeto ao modo de vida do indivíduo e da capacidade de adotá-lo. Já Hagberg (2012) afirma que a resistência de alguns idosos às novas tecnologias também pode ser interpretada pelo restrito conhecimento e experiência prática dessa parcela da população em lidar com o novo. Além disso, segundo o autor, as tecnologias são frequentemente desenvolvidas para os jovens, que são, em sua maioria, os primeiros a utilizá-las. Isso nos permite compreender que a subjetividade extrapola os limites da individuação do sujeito, constituindo um sistema organizado por processos simbólicos e emocionais na inter-relação com os processos históricos, culturais e sociais (GONZÁLEZ REY, 2005; MOLON, 2011).

Ao ser questionada sobre qual seria o motivo de a "participante 24" afirmar existir aparelhos de difícil uso para os idosos, a idosa expressa seu receio de acidentes futuros. Já a "participante 14" expressa uma opinião contrária, ao mencionar a importância da instrução para 
um bom êxito na utilização de tecnologias. Instrução possui dois sentidos, na fala da idosa. Em um primeiro momento, a participante se refere ao manual de informações para o uso que geralmente acompanha os produtos. Posteriormente, instrução recebe o significado de alfabetização. O fato de possuir curso superior, na opinião da participante, contribui de forma significativa para que a mesma não tenha dificuldades em manusear seus equipamentos.

[...] porque tem aparelho muito difícil. E, pode acontecer um desastre com eles (idosos) (Participante 24; 65 anos).

[...] se ler as instruções. Eu acho que são muito boas. Eu não quero mais lavar pratos na mão, essa coisa toda não. Eu acho que se as pessoas não quiserem saber, é diferente. Mas, tendo a instrução é bom demais. Não sei se, por exemplo, eu tenho curso superior (Participante 14; 80 anos).

A tecnologia é vista como algo difícil para a "participante 5", por exigir uma série de comandos para o seu funcionamento. Como a idosa já vivencia na prática essa realidade, acredita não ter dificuldade. Todavia, entende que enfrentaria obstáculos, caso não tivesse esse contato. O temor de acidentes faz com que a participante entenda que o uso de eletrodomésticos, como a fritadeira elétrica, cause acidentes domésticos em idosos, o que seria possível de ser evitado, caso os produtos fossem "mais práticos". Dessa forma, entende-se, pela sua fala, que os idosos que não possuem uma vivência anterior com a tecnologia são mais suscetíveis de se envolverem em incidentes com "novas tecnologias", os quais poderiam ser evitados, caso os eletrodomésticos fossem menos complexos de manusear.

Olha, se fosse para eu começar agora seria complicado entendeu? Porque a tecnologia, esse negócio de aperta ali, aperta aqui é difícil. Acho que teria que ser uma coisa mais prática para o idoso [...] Não, eu acho até perigoso. Porque, por exemplo, uma fritadeira de batatas né! A pessoa põe lá a batata, uma assadeira de frango, a pessoa põem lá e não sabe usar direito, acaba queimando (Participante 05; 66 anos).

A "participante 31", por sua vez, afirma que os eletrodomésticos que estão sendo lançados recentemente no mercado não são fáceis de serem manuseados pelos idosos, pois é necessário "estudar" para usá-los, além de pedir ajuda de terceiros para conseguir um bom êxito. A idosa se vê como uma "pessoa lenta", ou seja, seu processo de aprendizagem é vagaroso. Todavia, entende que, ao construir conhecimento de como manipular a tecnologia, da forma que melhor Ihe satisfaz, não possui dificuldades.

Os (eletrodomésticos) que tão lançando agora "pras" pessoas idosas, não. "Cê" tem que estudar, saber informar direitinho, pedir ajuda "pra" conseguir sabe! Eu sou assim, eu sou lenta, mas depois que eu pego o jeito vai (Participante 31; 65 anos). 
Hagberg (2012) ressalta que considerar-se capaz de utilizar uma tecnologia é uma questão de informação, de educação e também de persuasão. Dessa forma, a idade cronológica não é o único fator que interfere na aceitação e no uso de tecnologias, principalmente por idosos (PEIXOTO; CLAVAIROLLE, 2005). A complexidade dos aparelhos e de suas inúmeras funções é um dos motivos que resultam na inibição de uso para os idosos, que acabam por deixá-los de lado, ou delegar seu uso a outras pessoas, por medo de que algo aconteça com o dispositivo ou consigo mesmo (PEIXOTO; CLAVAIROLLE, 2005; RAYMUNDO, 2013).

O "participante 16" afirma existirem muitos idosos que não sabem manusear as "novas tecnologias". Ao narrar uma experiência vivenciada com a mãe de 83 anos de idade, é possível perceber, em sua fala, que a resistência de sua mãe estava atrelada ao anseio em utilizar um artefato que não fez parte de sua cultura técnica ao longo da vida, e não apenas em desconhecer a manipulação do eletrodoméstico.

Só que tem muito idoso que nem sabe mexer com isso né! Igual minha mãe mesmo, minha mãe tá com 83 anos. Aí ela custou mudar a cabeça "pra" comprar uma máquina de lavar roupa. Ela falou "Eu num sei mexer com isso não!" Aí depois... Aí eu falei "A senhora precisa". Agora ela usa. Usa tranquila (Participante 16; 65 anos).

Em sua fala, o "participante 03", em um primeiro momento, busca justificar sua dificuldade no uso de seus aparelhos, devido ao acesso tardio. Posteriormente, o idoso afirma que o problema não está no aparelho e sim nele, visto que possui "preguiça mental". Dessa forma, é possível entender que existe uma espécie de culpa em ambas as partes, sendo a do indivíduo maior que a da tecnologia. Entretanto, o idoso entra em contradição ao dizer que os equipamentos possuem muitos detalhes, o que dificulta o seu uso. Ao exemplificar o uso do forno de micro-ondas por crianças, o participante acredita que estes indivíduos aprendem a utilizar o equipamento de forma mais rápida que os idosos, pois desde cedo crescem cercados de tecnologias, se adaptando aos artefatos com maior rapidez, ao contrário das pessoas mais velhas.

Às vezes é porque nós não tivemos acesso "cê" tá entendendo? Às vezes a culpa é da nossa idade, eu tenho 78 e ela (esposa) 75 . Então, é preguiça mental às vezes. Eu não acho que é culpa da... Eu tô em dúvida. Assim, eu acho que não é culpa do aparelho sabe! É culpa nossa. É mais culpa nossa que do equipamento. É detalhe demais. Não digo que eles (planejadores) estão errados, mas "pra" nós fica difícil [...] o micro-ondas, nós dois aqui, a gente fica estupefado quando vê uns meninos tudo pequeninho na sua frente " $\mathrm{Ti}, \mathrm{Ti}, \mathrm{Ti}$ ". Eu não entendo. Eles pegam muito mais rápido que nós. Nós não tivemos o treinamento. Eu reconheço a nossa incapacidade, mas eu não quero dizer que o fabricante tá errado [...] Nós não crescemos com isso. Não estamos afeiçoados às novas tecnologias (Participante 03; 78 anos).

A responsabilidade de dominar um artefato tecnológico é comumente destinada aos usuários, ou seja, "[...] os erros são sempre humanos, mesmo quando estão inscritos em um 
sistema tecnológico complexo e ativo" (PEIXOTO; CLAVAIROLLE, 2005, p.39). Dessa forma, a tecnologia é considerada isenta de qualquer responsabilidade, o que reverbera em uma imagem negativa de si, caso o uso de um determinado produto não tenha o resultado esperado.

A fala do "participante 03" possibilita uma reflexão sobre uma característica marcante da subjetividade que, segundo Tacca; González Rey (2008), é seu caráter histórico, ao abranger a história das diferentes relações do sujeito nos contextos da vida cotidiana, essencialmente cultural, marcada pelos sistemas de valores e construções simbólicas atuais dos grupos de referência, o que a identifica como uma intricada rede.

\section{Aspectos apontados para não aquisição de novos eletrodomésticos pelos idosos}

Sobre a participação dos idosos na decisão de compra de novos eletrodomésticos, dos 38 participantes, quatro, sendo três do gênero masculino e um do gênero feminino, afirmaram não se envolver nesta questão. Os outros 34 idosos disseram opinar e, quando se interessam, se responsabilizar pela atividade. Os participantes que afirmaram não serem responsáveis por adquirir ou se envolver nos assuntos relacionados às tecnologias domésticas foram então questionados sobre quem era responsável por novas aquisições. Entre os homens, cônjuge e filhos foram citados como os compradores. Já para a idosa, os filhos decidem pela compra de novos equipamentos.

Os idosos também foram questionados sobre os motivos de não disporem de outros tipos de eletrodomésticos em suas residências. No Quadro 1, as respostas foram categorizadas conforme os sentidos que foram atribuídos em suas explicações.

Quadro 1: Motivações dos idosos para não aquisição de novos eletrodomésticos, 2018.

\begin{tabular}{|c|c|c|}
\hline \multicolumn{2}{|l|}{ CATEGORIAS } & SUBCATEGORIAS \\
\hline \multirow{9}{*}{$\begin{array}{c}\text { Fatores } \\
\text { Intrínsecos }\end{array}$} & \multirow{6}{*}{ Necessidade } & Não faz falta \\
\hline & & Não tem utilidade \\
\hline & & Falta de interesse \\
\hline & & Substituição por outros produtos \\
\hline & & Satisfação com os que possuem \\
\hline & & Não vai usar \\
\hline & Medo & Acidentes futuros \\
\hline & \multirow{2}{*}{ Aprendizagem } & Dificuldade de uso \\
\hline & & Falta de conhecimento da existência do produto \\
\hline \multirow{7}{*}{$\begin{array}{c}\text { Fatores } \\
\text { Extrínsecos }\end{array}$} & \multirow{5}{*}{ Dinheiro } & Renda baixa \\
\hline & & Consumo de energia \\
\hline & & Consumismo \\
\hline & & Crise financeira \\
\hline & & Prioridade em relação à saúde \\
\hline & Tempo & Pouca presença em casa \\
\hline & Espaço & Prioridade no novo ambiente \\
\hline
\end{tabular}

Fonte: Dados da pesquisa, 2017. 
Como pode ser observado no Quadro 1, existem variáveis intrínsecas ${ }^{4}$ e extrínsecas ao sujeito, na decisão de não aquisição de novos produtos. As variáveis intrínsecas encontradas foram: necessidade, aprendizagem e medo. Já como variáveis extrínsecas foram verificados dinheiro, espaço e tempo.

Nas falas abaixo, podemos perceber questões relacionadas à necessidade, que é a argumentação mais citada entre os idosos.

[...] A lava-louças, além de lavar poucas peças, poucas peças que você coloca. O mixer também, "cê" vai no liquidificador, você faz no liquidificador né! $E$, tem até hoje, o liquidificador que você aperta né! Ele faz a função (Participante 05; 66 anos).

Ah, nunca tive interesse. Conhecer assim, igual esse multiprocessador, eu conheço porque já vi. Mas, não me deu aquela vontade de ter não. Esse outro aí (mixer) eu tô sabendo o quê que é agora. A cafeteira também eu conheço, mas, nunca me interessei em comprar não (Participante 26; 70 anos).

Quando os meus filhos "tava" tudo dentro de casa, tudo solteiro, a máquina que me ajudava demais. Mas, agora só eu e meu esposo. Eu peguei e dei pra minha nora, essa que tem quatro filhos. Aí "num" achei necessário não. A panela de arroz, não achei necessidade porque é tão pouquinha comida que faz aqui né! (Participante 04; 74 anos).

Eu não tenho porque eu não vou usar. Eu acho que isso, "pra" deixar numa forma mais clara, num é uma boa. Então, "pra" quê que eu vou ter né! E, quando eu era casado, a minha esposa era viva, num tinha esses negócios (Participante 15).

A "participante 05" afirma que alguns produtos, como lava-louças e mixer, são desnecessários em seu cotidiano, pois possui outros eletrodomésticos que executam de forma satisfatória suas atividades diárias. Peixoto; Clavoirolle (2005) ressaltam que as "novas tecnologias" sempre estiveram associadas à modernidade. Segundo as autoras, a relação que os idosos estabelecem com as "novas tecnologias" faz parte de uma estratégia identitária construída por fatores individuais e sociais. Dessa forma, quando os idosos afirmam possuir determinados produtos, apontam para duas estratégias identitárias diferenciadas e que se traduzem, uma como uma referência à velhice, e a outra como menção à modernidade.

De acordo com a fala da "participante 26", podemos observar que a idosa diz não ter vontade de adquirir alguns produtos que conhece e também revela não conhecer outros apresentados nesta pesquisa. Peixoto; Clavairolle (op.cit.) afirmam que estudos sobre os efeitos de "novas tecnologias" sobre as pessoas de mais idade mostram que os idosos realizam uma seleção, em que privilegiam os objetos tecnológicos que apresentam maior simplicidade de

\footnotetext{
${ }^{4}$ É de entendimento deste trabalho a existência de estudos que revelam a íntima relação entre fatores intrínsecos e extrínsecos. Todavia, para fins didáticos, optou-se pela separação destes.
} 
manipulação e que atendam suas reais necessidades. Dessa forma, descartam aqueles que não se encaixam nos dois critérios mencionados. Já autores como (KAUFMANN, 1992; 1995; CARADEC, 1999), citados por Peixoto; Clavairolle (2005), afirmam que várias pesquisas evidenciam que a hostilidade por parte de idosos em relação às "novas tecnologias" é mais resultado de uma desconfiança diante do novo, do que falta de interesse pela inovação tecnológica e os serviços prestados.

A diminuição da família foi a motivação da "participante 04" para não possuir determinados eletrodomésticos, como a máquina de lavar e a panela elétrica, o que vai de encontro com o estudo de Peixoto; Clavairolle (2005) quando discorrem que a nuclearização se caracteriza como uma mudança social na vida dos idosos, refletindo também no uso e na aquisição de diferentes tipos de tecnologias cotidianamente.

O "participante 15" ressalta que não adquire "novas tecnologias", pois não irá usar. Para o idoso, não é apropriado comprar um produto que não será utilizado, o que também está relacionado ao fator dinheiro. Outra questão relatada é o fato de que a responsabilidade de decisão da aquisição de novos artefatos era da esposa. Hoje, viúvo, revela que, quando casado, não existiam no mercado os produtos encontrados atualmente. A fala do idoso corrobora Silva (1998b) ao evidenciar que, pela responsabilização das atividades da casa ser da mulher, esta possui também poder na decisão de aquisição dos equipamentos, por ser ela quem desenvolverá tais tarefas.

O medo de utilizar foi citado por duas idosas ao mencionarem o motivo de não possuírem o forno de micro-ondas. Inicialmente, a "participante 24" disse não ter interesse, mas em seguida revelou ser o medo de acidentes futuros com o neto o real motivo que a impede de adquirir o produto. Por sua vez, a "participante 19" relatou ter medo de sofrer um acidente, pois já teve uma experiência negativa com o produto.

$E$ já falei que nem quero [...] porque eu tenho medo. Porque aqui esse menino que mora comigo, ele não tem muito noção do que vai ligar. As coisas dele ele abre. Até pouco tenho eu "panhei" ele lá dentro do quarto mexendo que dava, apagava as luzes. Dava curto circuito (Participante 24; 65 anos).

Tenho um medo daquele "trem" explodir comigo, nossa mãe! Quando alguém vai esquentar uma farofa, minha filha, mas é paf, o ovo né! Dá aqueles estrondo. Eu tenho um medo danado boba! (Participante 19).

Peixoto; Clavairolle (2005) destacam que a não utilização de um objeto está relacionada aos riscos que o sujeito acredita que o mesmo possui. As autoras discorrem sobre a complexidade que é, para o idoso, fazer funcionar, por exemplo, o forno de micro-ondas, uma vez que não tiveram contato com o artefato durante sua trajetória, não desenvolvendo recursos 
técnicos necessários para um bom êxito.

A "participante 32", ao contrário dos demais idosos, revelou ter vontade de comprar o forno de micro-ondas. Contudo, ressaltou que o fato de não saber utilizar a impede de adquirir o produto.

Tenho vontade de comprar, mas tenho dificuldade de mexer. Não comprei ainda porque não sei mexer, se eu soubesse já tinha comprado, porque é uma beleza rebentar pipoca (Participante 32; 74 anos).

Para que ocorra a apropriação de um objeto técnico, o usuário necessitará de uma imersão na cultura técnica daquele objeto. Essa imersão pode ser facilitada pela mediação exterior, por meio da sociabilidade dentro e fora do meio familiar. Para Peixoto; Clavairolle (2005), a mediação familiar no acesso a "novas tecnologias" constitui um elo com o mundo exterior, ao permitir o contato com o grupo familiar, a vizinhança e o mundo, bem como permitir a integração dos aparatos domésticos, seja por estímulos e conselhos para aquisição, seja por meio de presentes dados aos idosos.

Com relação ao fator dinheiro, nas falas abaixo podem ser observadas questões como falta de recursos, consumismo, falta de atenção a maneiras mais fáceis de aquisição dos eletrodomésticos, prioridade em relação a outras questões pessoais e a crise financeira vivenciada pelo país.

Ah, porque eu não tenho condições de comprar porque a renda minha aqui é quase que conta de pagar as contas, e principalmente essa época agora que tá com essa crise toda aí né! (Participante 07; 66 anos).

Eu não sou assim, tipo consumista, que apareceu ali eu tenho que ter. Eu não sou assim não (Participante 28; 65 anos).

Isso aí é lerdeza mesmo da gente. Sempre tem promoção, bem que a gente podia comprar. Mas, só que vem umas outras coisas mais "pra" gente comprar [... Então, eu penso assim, primeiro eu vou cuidar da minha saúde [...] (Participante 23; 74 anos).

Ah, não sei [...] o pagamento ainda não saiu né! Eu gosto de comprar assim, se for à prestação tem que ser de "duas vez". Se for dividir é muito, eu acho que aquilo vai... juros né! (Participante 29; 71 anos).

De acordo com Silva (2011), além das dificuldades impostas pelas tecnologias, existem fatores que influenciam no uso destes objetos pelos idosos como, por exemplo, o custo. Outra questão influenciadora é a representação que o sujeito tem do consumo. A "participante 28 " entende que adquirir produtos sem necessidade é ser consumista, imagem que não quer para si.

Apesar de muitos comércios usarem de diferentes estratégias para atrair o consumidor, 
como promoções ou formas mais acessíveis de quitar a compra, como o parcelamento, a "participante 23" ressalta o medo de desenvolver dívidas. Já a "participante 29", apesar de evidenciar a falta de atenção à essas estratégias promovidas pelas empresas, destaca a prioridade com outros gastos mais importantes, como sua saúde. Peixoto; Clavairolle (2005) afirmam que o fator econômico é crucial para as pessoas de renda mais baixa, pois estas priorizam as despesas mais importantes. Dessa forma, ocorre uma limitação da capacidade de compra, fazendo com que renunciem a equipamentos de alto custo ou considerados de pouca serventia.

Para Silva (1998a), é um equívoco pensar as atividades da vida doméstica apenas sob uma ótica da economia, seja de tempo ou financeira. Para a referida autora, é possível concluir que se compra muito trabalho doméstico, visto que as aquisições resultam em uma maior autonomia para as mulheres, por contribuir para uma menor sobrecarga na realização das tarefas cotidianas. Diante da fala de Silva, é possível perceber que o uso frequente de tecnologias domésticas pelas mulheres sempre esteve ligado ao trabalho mais oneroso, e não para execução de tarefas básicas ou diversão.

O tempo, ou falta de tempo, no caso da "participante 09", como pode ser observado abaixo, é razão da mesma não possuir equipamentos como o forno de micro-ondas. A idosa ressaltou que não é o fator dinheiro que a impede de adquirir o produto, mas sua ausência em casa, uma vez que possui um emprego noturno.

É, eu trabalho e assim... Quase não vivo dentro de casa "pra" poder usar. Porque o micro-ondas você tem que morar dentro de casa né! E, assim, não é que ele seja caro, até dá "pra" comprar [...] Mas, eu não compro por isso, por eu não ter muita presença dentro de casa tá entendendo? (Participante 09; 64 anos).

Espaço foi outra questão mencionada pelos idosos. Foi necessário que a "participante 10" fizesse uma escolha de qual produto levar para o novo endereço, caracterizando, neste caso, também o fator prioridade entre possuir ambos os eletrodomésticos, conforme a fala abaixo:

Olha, o tanquinho eu tinha onde eu morava e tinha espaço. Quando eu mudei "pra cá" não coube os dois. Trouxe só a máquina (Participante 10; 75 anos).

Oh, o tanquinho, eu já tive, mas eu troquei pela máquina. É "pra" mim não ocupar mais espaço né! (Participante 2; 68 anos).

Todavia, é importante ressaltar que, no caso da "participante 10", a prioridade está relacionada à ausência de espaço. Já a "participante 2" deixa claro que preferiu trocar o tanquinho pela máquina para ocupar menos espaço. Porém, igualmente, pode-se observar a 
prioridade na escolha de um produto com mais funções.

As afirmativas sobre a questão do espaço e sua relação na escolha de artefatos tecnológicos contribuem para uma reflexão em termos de como os idosos adaptam os objetos às suas necessidades cotidianas. De acordo com os resultados encontrados pelo estudo, podese perceber a ocorrência de diferentes questões que permeiam a decisão de aquisição ou rejeição de determinados artefatos pelos idosos.

\section{CONSIDERAÇÕES FINAIS}

A pesquisa evidenciou que a representação que os idosos participantes deste estudo possuem acerca do "ser idoso" é algo distante da realidade vivenciada por eles. Foi possível observar que eles não se enxergam como idosos, ou seja, idoso é o outro. Observou-se que as representações sociais acerca do envelhecimento e da velhice aparecem de maneira direta e indireta, definidas por sistemas e práticas compartilhadas socialmente. A relação entre idosos e tecnologias domésticas aparece como inserida em uma produção subjetiva social e individual, possuindo um valor central na forma como os sujeitos se relacionam com os artefatos tecnológicos.

No que diz respeito aos fatores envolvidos na decisão de não aquisição de novos eletrodomésticos, observou-se a existência de motivações particulares de cada idoso. Diante disso, compreende-se a relação sujeito/tecnologia como imbricada em uma complexa teia de fatores intrínsecos e extrínsecos ao sujeito. Sendo assim, generalizar os fatores decorrentes do envelhecimento como responsáveis pela recusa na aquisição de novas tecnologias, sejam elas para uso no âmbito doméstico ou outros espaços da vida cotidiana, contribui negativamente para a relação da pessoa idosa com os artefatos tecnológicos, visto que é necessário observar as estratégias que estes indivíduos utilizam para se negar a incorporar o "novo" em sua vida diária.

\section{REFERÊNCIAS}

AMARAL JUNIOR, J. C. Estudo da interação idoso e tecnologia no universo doméstico e sua relação com a autonomia. 2013. 154 f. Dissertação (Mestrado em Economia Doméstica) Universidade Federal de Viçosa, Viçosa, MG, 2013.

BARDIN, L. Análise de conteúdo. Lisboa: Edições 70. 2009.

BAPTISTA, M. M. R. T. Tempos de ser e ciclo vital: elaborações culturais contemporâneas. In: MARTINS, J. C. O. (Ed.). Seminário Ócio e Contemporaneidade: tempo social e envelhescência nas culturas contemporâneas, 6, 22 e 23 de agosto de 2013, Fortaleza.

Fortaleza: Unifor, 2013. 
BORGES, G, M.; CAMPOS, M. B.; SILVA, L. G. C. Transição da Estrutura Etária no Brasil: Oportunidades e Desafios para a Sociedade nas Próximas Décadas. In: ERVATI, L. R.; BORGES, G. M.; JARDIM, A. P. [org]. Mudança Demográfica no Brasil no Início do Século XXI: Subsídios para as Projeções da População. IBGE, Rio de Janeiro, p. 138-151.2015.

CAMARANO, A. A.; KANSO, S.; MELLO, J. L. Como vive o idoso brasileiro. In: CAMARANO, A. A. (Org.). Os novos idosos brasileiros: muito além dos 60? - Rio de Janeiro: IPEA, p. 25- 59. 2004.

CAMARANO, A. A.; BELTRÃO, K. I.; PASCOM, A. R. P.; MEDEIROS, M.; CARNEIRO, I. G.; GOLDANI, A. M.; VASCONCELOS, A. M. N.; CHAGAS, A. M. R.; OSÓRIO, R. G. Como vai o idoso brasileiro? Rio de Janeiro: IPEA, 1999.

GONZÁLEZ REY, F. L. As representações sociais como produção subjetiva: seu impacto na hipertensão e no câncer. Psicologia: Teoria e Prática, v.8, n.2, p.869-885. 2006.

GONZÁLEZ REY, F. L. Sujeito e subjetividade: uma aproximação histórico-cultural. São Paulo: Pioneira Thomson Learning, 2005.

HAGBERG, J. E. Being the oldest old in a shifting technology landscape. In: LOOS, E.; HADDON, L.; MANTE-MEIJER, E. (Ed.). Generational Use of New Media. Surrey: Ashgate, p. 89-106. 2012.

LIMA FILHO, D. L. O conceito de tecnologia como construção social: as dimensões sócioculturais da produção e apropriação do conhecimento. XXVI Congreso de la Asociación Latinoamericana de Sociología. Asociación Latinoamericana de Sociología, Guadalajara. 2007.

MAGALHÃES, D. N. A invenção social da velhice. Rio de Janeiro: Editora Papagaio Ltda. 1989.

MENDES, M. B.; GUSMÃO, J. L.; FARO, A. C. M.; LEITE, R. C. B.O. A situação social do idoso no Brasil: uma breve consideração. Revista Acta Paulista de Enfermagem, v. 18, n. 4, p. 422426. 2005.

MOLON, S. I. Notas sobre constituição do sujeito, subjetividade e linguagem. Psicologia em Estudo, v. 16, n. 4, p. 613-622. 2011.

MOREIRA, V.; NOGUEIRA, F. N. N. Do indesejável ao inevitável: a experiência vivida do estigma de envelhecer na contemporaneidade. Psicologia USP, São Paulo, v. 19, n.1, p. 5979. 2008.

MOSCOVICI, S. Representações sociais: investigações em psicologia social. 5 ed. Petrópolis, RJ: Vozes, 2007.

NERI, A. L. O fruto dá sementes: processos de amadurecimento e envelhecimento. In: (Org.). Maturidade e velhice: trajetórias individuais e socioculturais. Campinas:

Papirus, p. 11-52. 2001. 
ONU. A ONU e as pessoas idosas. 2016. Disponível em: <https://nacoesunidas.org/aca o/pessoas-idosas/>. Acesso em: 03 jun. 2019.

PEIXOTO, C. E.; CLAVAIROLLE, F. Envelhecimento, políticas sociais e novas tecnologias. Editora FGV. Rio de Janeiro, 2005.

PEREIRA, C.; NEVES, R. Os idosos na aquisição de competências TIC. Educação, Formação \& Tecnologias, v. 4, n.2 p.15-24. 2011.

RAYMUNDO, T. M. Aceitação de tecnologias por idosos. 2013. 89 f. Dissertação (Mestrado) - Curso de Bioengenharia, Universidade de São Paulo, São Carlos, 2013.

ROSSATO, M..; MARTÍNEZ, A. M. O movimento da subjetividade no processo de superação das dificuldades de aprendizagem escolar. In: Grupo de pesquisa: aprendizagem, escolarização e desenvolvimento humano. Disponível em:< http://www.grupeci.fe.ufg.br/up/693/o/TR33.pdf>. Acesso em: 02 jun. 2019.

ROZENDO, A.; JUSTO, J. S. Velhice e terceira idade: tempo, espaço e subjetividade. Revista Kairós Gerontologia, v.14, n.2, p.143-159. 2011.

SCHNEIDER, R. H.; HIRIGARAY, T. Q. O envelhecimento na atualidade: aspectos cronológicos, biológicos e sociais. Revista Estudos de Psicologia, v. 25, n. 4, p. 585.593. 2005.

SILVA, D. O. Uso de aparelhos eletrônicos por idosos em ambientes domésticos. 2011. 75 f. Dissertação (Mestrado) - Curso de Ciências, Universidade de São Paulo, São Carlos, 2011.

SILVA, L. R. F. From old age to third age: the historical course of the identities linked to the process of ageing. História, Ciências, Saúde, v.15, n.1, p.155-168. 2008.

SILVA, E. B. Teorias sobre trabalho e tecnologias domésticas- implicações para o Brasil.1998a.

SILVA, E. B. Tecnologia e vida doméstica nos lares. Cadernos Pagu, v.10, p. 21- 52, $1998 \mathrm{~b}$.

SILVEIRA, C. M. H.; OSTERNE, M. S. F. A mulher é Eva, o homem é Adão? Reflexões sobre o significado de ser homem e de ser mulher na sociedade. Caderno Espaço Feminino, v. 27, n. 1, p. 1-18. 2014.

TACCA, M. C. V. R..; GONZÁLEZ REY, F. L. Produção de sentido subjetivo: as singularidades dos alunos no processo de aprender. Psicologia, Ciência e Profissão, v. 28, n.1, p. 38-161. 2008.

TEIXEIRA, S. M. de O.; MARINHO, X. S.; CINTRA JUNIOR, D. de F.; MARTINS, J. C. de O. Reflexões acerca do estigma do envelhecer na contemporaneidade. Estudos Interdisciplinares do Envelhecimento, v. 20, n. 2, p. 503-515, 2015. 